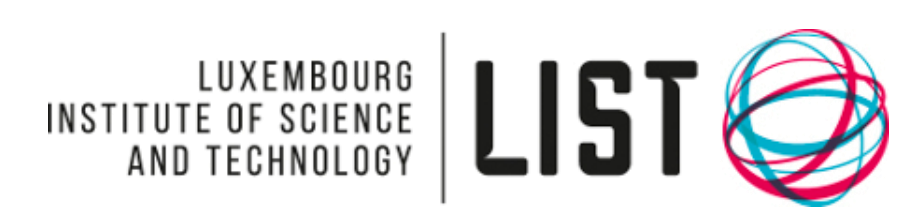

Luxembourg National Research Fund

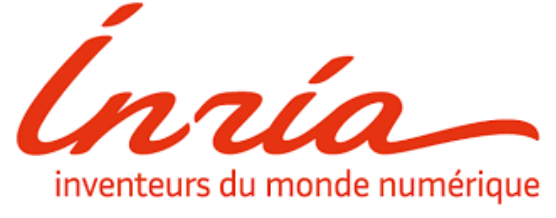

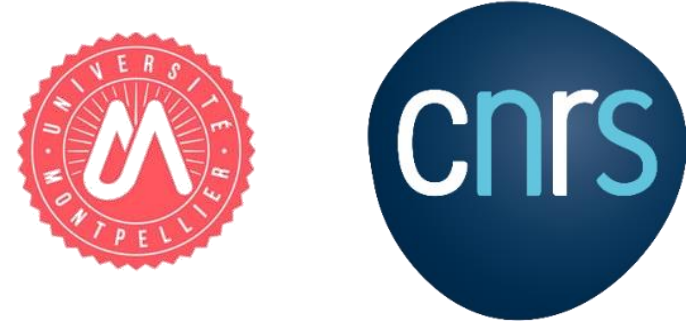

\title{
Towards fast large-scale flood simulations using 2D Shallow water modelling with depth-dependant porosity
}

\author{
Vita AYOUB ${ }^{1,2,3}$, Carole DELENNE2,3, Patrick MATGEN ${ }^{1}$, Pascal FINAUD-GUYOT ${ }^{2-3}$, Renaud HOSTACHE ${ }^{1}$
}

[1] Luxembourg Institute of Science and Technology, Environmental Research and Innovation Department, Esch-sur-Alzette, Luxembourg [2] HydroSciences Montpellier, Université de Montpellier, CNRS, IRD, Montpellier, France

[3] Inria Lemon, CRISAM - Inria Sophia Antipolis - Méditerranée, France

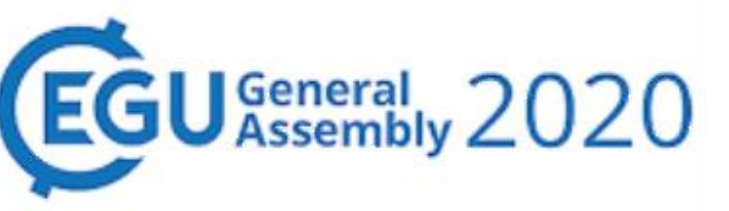

Online | 4-8 May 2020
Session NH1.1 - Flood risk modelling and assessment (with

a special focus on uncertainty)

Chat time: Wednesday, 6 May 2020, 8:30-10:15 


\section{Outline}

1. The CASCADE project, main hypothesis and objectives.

2. Large scale flood modelling at high resolution: context and challenges.

3. Research question.

4. Study site and available data.

5. Model setup.

6. Results.

7. Conclusion.

8. References. 


\section{The CASCADE project}

- A contribution to the CASCADE (Combining earth observation with a large scale model cascade for assessing flood hazard at high spatial resolution) project.

- The main working hypothesis of the CASCADE project: the joint use of Satellite Earth Observation (SEO) - derived soil moisture and flood maps will allow constraining model predictions, with a reduced need of in situ hydrometric data.

- Objective of the CASCADE project: the production of flood hazard maps over two to three test areas. This will contribute in establishing SEO-based early warning systems at a large scale by combining remote sensing and hydraulic modelling through data assimilation.

- Our objective: the development of modelling framework for large scale hazard mapping using a hydraulic model. The modelling suite SW2D (Shallow Water 2 Dimensions) under constant development at HydroSciences Montpellier since 2002 will be used with the Depth-Dependant Porosity (DDP). 


\section{Context and challenges}

- A flood is a multi-scale phenomena: it occurs on a large scale. However, small scale features affect flood propagation. They thus need to be well represented in the model.

- Accurate results in conventional Shallow Water models require a fine meshing for representing complex topographic variations, which implies expensive computational costs.

- Porosity-based models solve the upscaled Shallow Water Equations with integrated porosity. The sub-grid features are dealt with even when using coarse meshing. This allows saving enormous processing times.
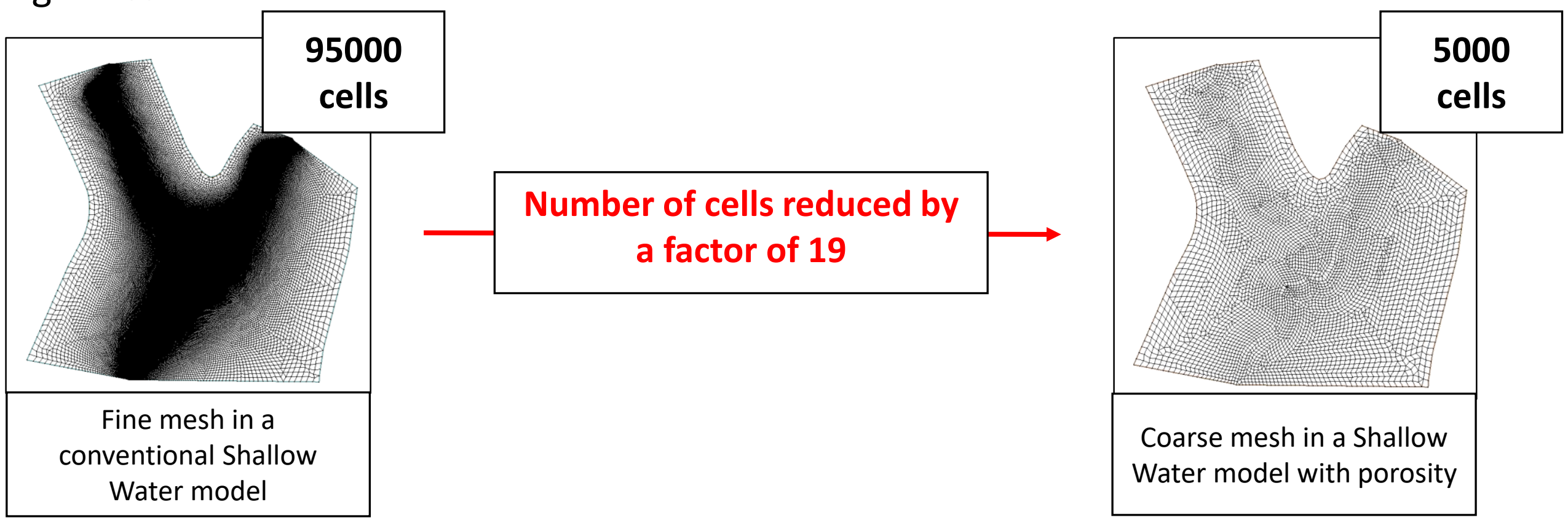


\section{Research question}

- Porosity = fraction of the cell (or edge) available to the water flow. It is equal to unity when the cell is completely wet, at its highest ground elevation.

- We distinguish storage porosity $\left(\phi_{\Omega}\right)$ inside the cell from connective porosity $\left(\phi_{\Gamma}\right)$ on cell edges.

- Research question: How can porosity be represented through a grid cell in SW2DDDP model?
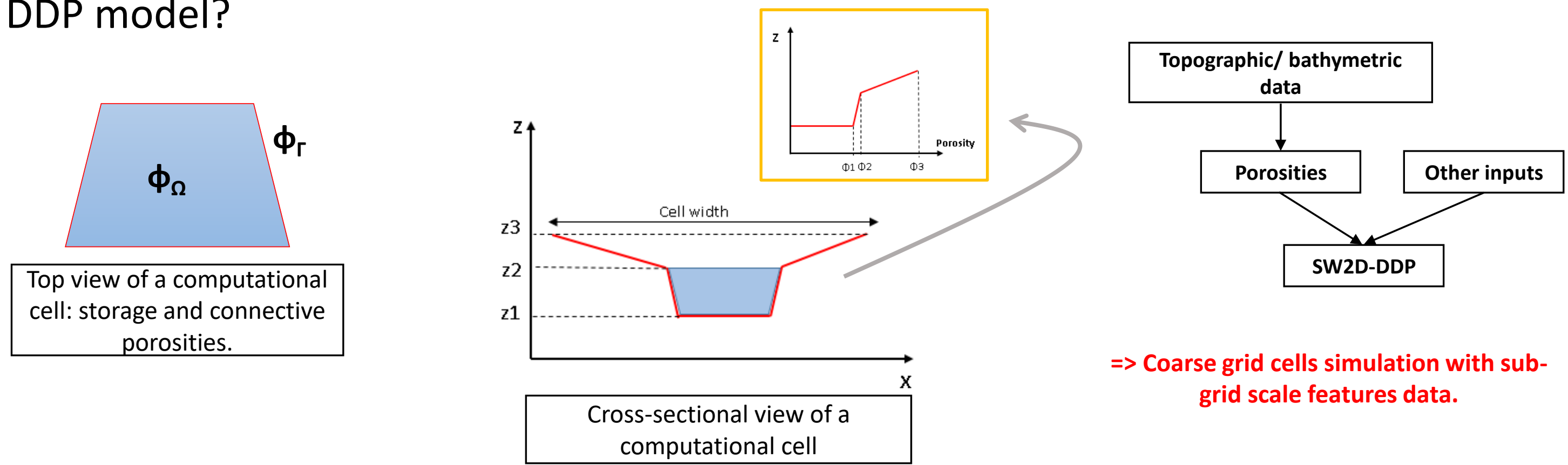


\section{Model setup}

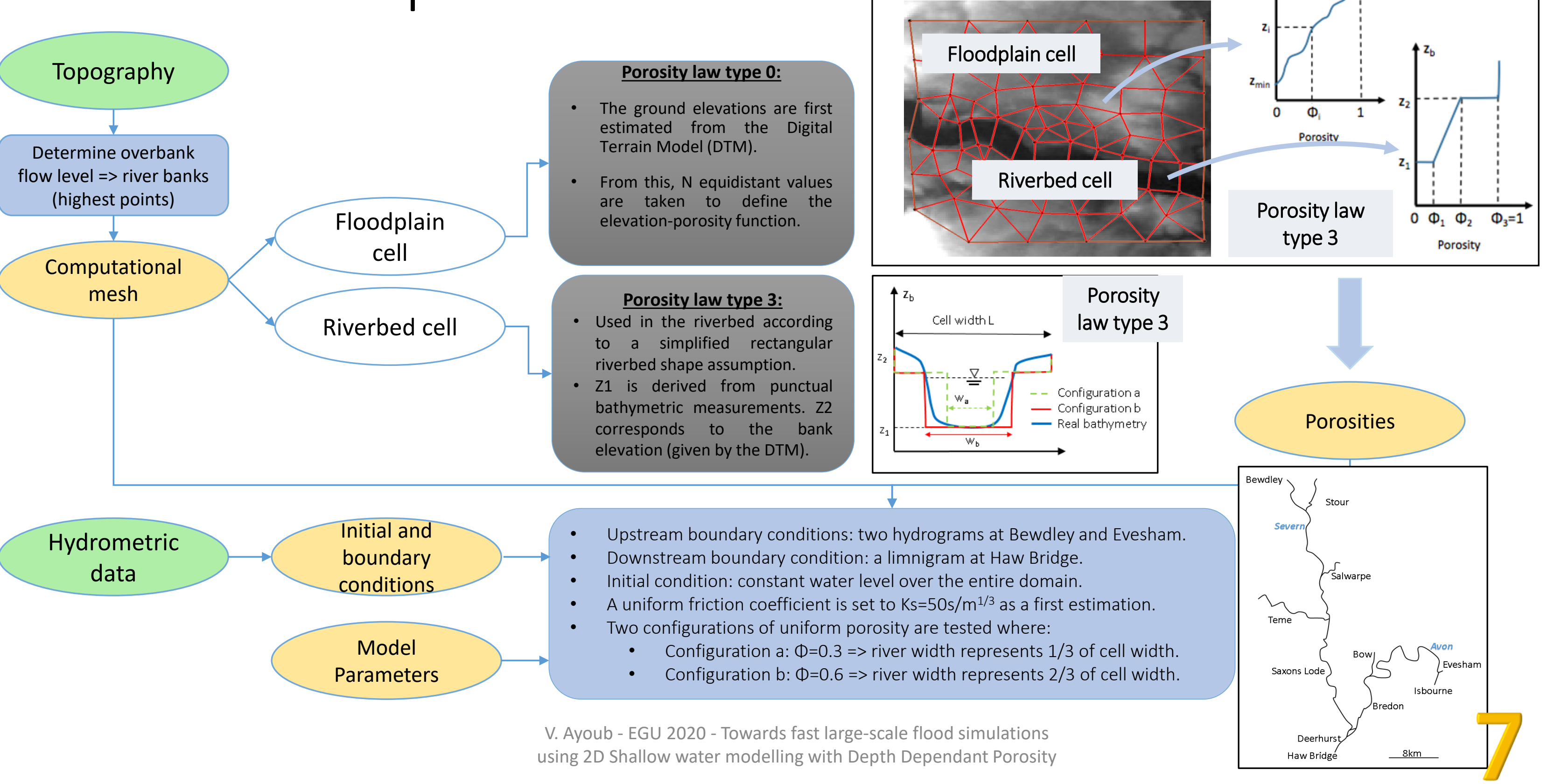




\section{6a. Water level assessment}

Comparison of water levels in the downstream part of the river to assess the hydraulic model performance while changing the global porosities in two configuration tests, using the Root Mean Square Error (RMSE) metric.

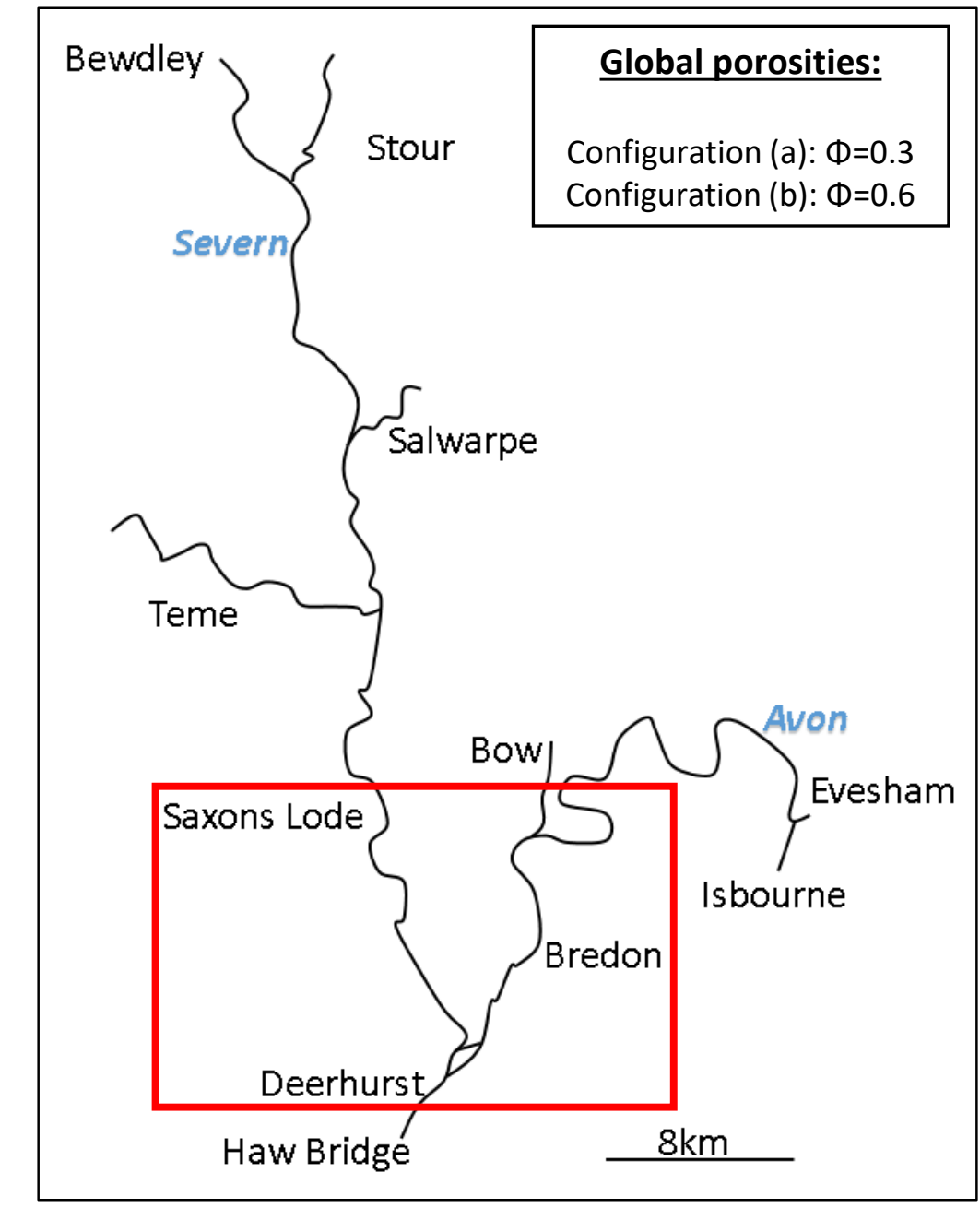

\begin{tabular}{|c|cc|cc|cc|}
\hline & \multicolumn{2}{|c|}{ Saxons Lode } & \multicolumn{2}{c|}{ Bredon } & \multicolumn{2}{c|}{ Deerhurst } \\
\hline RMSE $(\mathrm{a})$ & & 0.854 & & 0.886 & & 0.261 \\
\hline RMSE $(b)$ & $+13 \%$ & 0.987 & $-6 \%$ & 0.824 & $+16 \%$ & 0.419 \\
\hline
\end{tabular}

- Porosity change is influential on the model performance.

- Results are slightly better in configuration (a) for Saxons Lode and in configuration (b) for Bredon => parameters other than porosity affect the model's behaviour.

- The model is globally less sensitive to porosity at the downstream (Deerhurst). However the porosity change induces a bigger increase gap of $16 \%$. This is probably due to the backwater effects. 


\section{References}

1. Vincent Guinot, Sandra Soares-Frazão, Carole Delenne. Experimental validation of transient source term in porosity-based shallow water models. River Flow 2018 - Ninth International Conference on Fluvial Hydraulics, Sep 2018, Villeurbanne, France.

2. Vincent Guinot, C. Delenne, Antoine Rousseau, O. Boutron. Flux closures and source term models for shallow water models with depthdependent integral porosity. Advances in Water Resources, Elsevier, 2018, 122, pp.1-26.

3. Vincent Guinot. A critical assessment of flux and source term closures in shallow water models with porosity for urban flood simulations. Advances in Water Resources, Elsevier, 2017, 109, pp.133-157.

4. Vincent Guinot. Consistency and bicharacteristic analysis of integral porosity shallow water models. Explaining model oversensitivity to mesh design. Advances in Water Resources, Elsevier, 2017, 107, pp.43-55.

5. Vincent Guinot, Brett Sanders, Jochen Schubert. Dual integral porosity shallow water model for urban flood modelling. Advances in Water Resources, Elsevier, 2017, 103, pp.16-31.

6. Byunghyun Kim, Brett Sanders, James Famiglietti, Vincent Guinot. Urban flood modeling with porous shallow-water equations: a case study of model errors in the presence of anisotropic porosity. Journal of Environmental Hydrology, International Association for Environmental Hydrology, 2015, 523, pp.680-692.

7. Soares-Frazao, S., J. Lhomme, V. Guinot, \& Y. Zech (2008). Two-dimensional shallow-water model with porosity for urban flood modelling. Journal of Hydraulic Research 46(1), 45-64.

8. Guinot, V. \& S. Soares-Frazao (2006). Flux and source term discretization in two-dimensional shallow water models with porosity on unstructured grids. International Journal for Numerical Methods in Fluids 50(3), 309-345.

9. Defina, A. (2000). Two-dimensional shallow flow equations for partially dry areas. Water Resources Research 36(11), 3251-3264. 


\section{Thank you for your attention}

\section{Questions?}

vita.ayoub@list.lu 